\title{
BMJ Open What do patients expect? Assessing patient-centredness from the patients' perspective: an interview study
}

\author{
Stefan Zeh (D) , ${ }^{1}$ Eva Christalle (D) , ${ }^{1}$ Jördis M Zill (D) , ${ }^{1}$ Martin Härter (D) , \\ Andreas Block (D) , ${ }^{2}$ Isabelle Scholl (D) ${ }^{1}$
}

To cite: Zeh S, Christalle $\mathrm{E}$, Zill JM, et al. What do patients expect? Assessing patient-centredness from the patients' perspective: an interview study. BMJ Open 2021;11:e047810. doi:10.1136/ bmjopen-2020-047810

- Prepublication history and additional supplemental material for this paper are available online. To view these files, please visit the journal online (http://dx.doi.org/10.1136/ bmjopen-2020-047810).

Received 10 December 2020 Accepted 24 June 2021

Check for updates

(C) Author(s) (or their employer(s)) 2021. Re-use permitted under CC BY-NC. No commercial re-use. See rights and permissions. Published by BMJ.

${ }^{1}$ Department of Medical Psychology, University Medical Centre Hamburg-Eppendorf, Hamburg, Germany

${ }^{2}$ Department of Oncology, University Medical Centre Hamburg-Eppendorf, Hamburg, Germany

Correspondence to Stefan Zeh; s.zeh@uke.de

\section{ABSTRACT}

Objective Although there has been much conceptual work on patient-centredness (PC), patients' perspectives on PC were neglected. In a previous study, participating patients rated the relevance of 16 dimensions of an integrative model of PC as high to very high. However, it remained unclear which specific behaviours described in the dimensions were considered most relevant. Thus, the aim of the current study was to further explore which of the specific behaviours described in the model are especially relevant for the high ratings in the previous study. Methods and design We conducted semistructured interviews with 20 patients with chronic diseases (16 females, 4 males, mean age: 52 years). Patients answered questions regarding their experiences in the German healthcare system and how optimal healthcare would look like from their perspective. Furthermore, patients were asked to reflect on the most important aspects which they had mentioned in the interview before. Data were analysed via content analysis.

Results Participants addressed many different aspects of PC, but mostly focused on three major themes: (1) time appropriate access to care, (2) competence, empathy and being taken seriously by HCPs, (3) HCPs' individual consideration of each patient's situation (eg, wishes and needs). Minor themes were: (1) taking a holistic perspective of the patient, (2) patient-centred communication, (3) integration of multidisciplinary treatment elements, (4) transparency regarding waiting time and (5) reduction of unequal access to care.

Conclusion This study enriches the construct of PC by depicting essential aspects of PC from the patients' perspective. The results allow prioritising strategies to implement patient-centred care. Thus, this study helps to pursue the ultimate goal of fostering patient-centred healthcare delivery in Germany.

\section{INTRODUCTION}

Patient-centredness (PC) has been widely discussed over the last decades and its relevance in health policy, research and healthcare practice has been growing constantly. ${ }^{1-3}$ Different studies showed positive associations of PC with patient satisfaction, well-being, adherence, ${ }^{4}$ health behaviour, ${ }^{5}$ knowledge about the medical condition and recovery rate. $^{6}$ However, the term $\mathrm{PC}$ was lacking

\section{Strengths and limitations of this study}

Qualitative interviews enable an in-depth understanding of the patients' perspective.

- Interviews empower participants to freely talk about their experiences.

- Semistructured guidelines allow further probing for interesting and relevant insight.

- Differentiating between major and minor themes enables prioritisation of strategies to foster patientcentred care.

- Only few male participants and possible selfselection bias could make it harder generalising results.

conceptual clarity for a long time. ${ }^{7-12}$ Therefore, Scholl and colleagues ${ }^{8}$ developed an integrative generic model derived from literature. The model included 15 dimensions of $\mathrm{PC}$ and provides a comprehensive definition of PC (see figure 1). 'Here, patient-centred care is characterised by adequate access to continuous, and coordinated care and by competent, empathetic and respectful healthcare providers (HCPs). They work in interdisciplinary teams to integrate medical and non-medical care as needed, take a biopsychosocial perspective to understand the patient as a unique person and build a partnership with the patient through collaboration. Furthermore, they communicate clearly and communicate health information in an individualised manner, involve the patient and, where appropriate, the patient's family in health decisions. Finally, they encourage patients to take actions to improve their health and help patients to strengthen their physical and emotional well-being'.

This model was validated by assessing the views of different healthcare stakeholders on its relevance and clarity. ${ }^{13}$ While some representatives of patient organisations participated in this assessment, the perspective of individual patients was not included. 


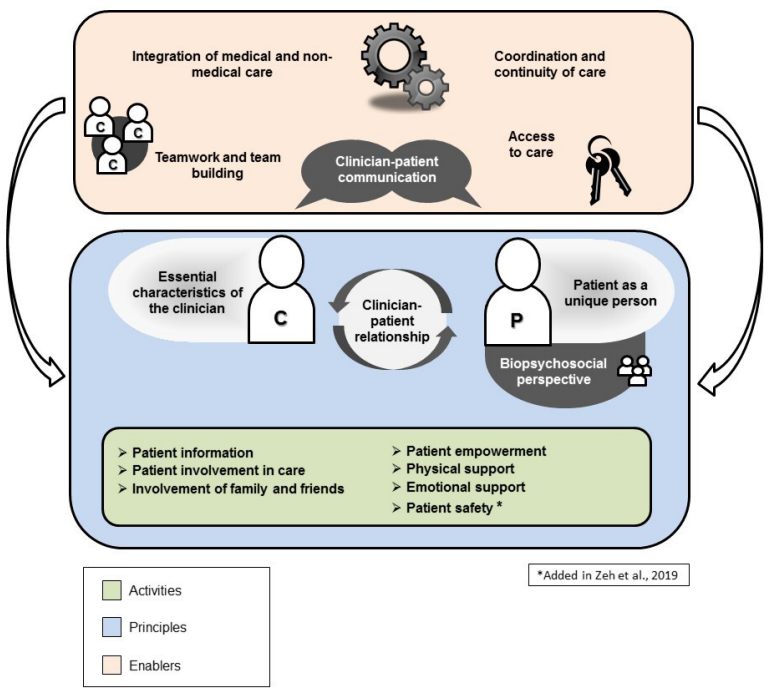

Figure 1 Integrative model of patient-centredness (Scholl et al 2014 ${ }^{8}$; Zeh et al $2019^{19}$ ).

Consequently, the conceptualisation of PC was still missing its most crucial aspect: the assessment and evaluation of PC in healthcare from the view of patients. ${ }^{14-16}$

Until now, there are only few international studies (eg, Maassen et $\mathrm{al}^{17}$ ) and even fewer German studies investigating patients' views on PC (eg, Zill et $\mathrm{al}^{13}$ or Vennedey et $\left.a l^{18}\right)$. However, it is decisive to assess relevance and current implementation of elements of PC in order to identify and prioritise strategies to foster its implementation. ${ }^{19}$ In this recent Delphi study, we asked patients to rate the aforementioned 15 dimensions regarding relevance. We found that every dimension was rated as (highly) relevant but also not well implemented from the patients' perspective. ${ }^{19}$ Additionally, 'patient safety' was added as a 16th dimension since it was missing so far from the patients' perspective. In general, this Delphi study yielded almost no variance between the different dimensions of PC in terms of relevance. Therefore, it was difficult to prioritise steps to foster implementation. Furthermore, it used a deductive approach by asking participants to rate dimensions derived from the literature $^{19}$ (figure 1) instead of specific behaviours which could be grasped more easily by patients. Therefore, the results were generated at a relatively high level of abstraction. Consequently, it would be interesting to know which specific aspects of patient-centred care patients mention without giving out restricting dimensions. For example, it could compliment the results of the Delphi study if patients were to mention respect and empathy on their own without researchers prompting them in this study. By doing so, results more in depth on the level of specific aspects instead of broad dimensions could help prioritising and implementing the most relevant topics of patient-centred care.

This study therefore aims at further exploring the patients' perspective on PC using qualitative interviews in order to better interpret the results of the Delphi study and to prioritise implementation strategies.

\section{METHODS}

\section{Study design}

We conducted a qualitative study using semistructured interviews, guided by Consolidated criteria for Reporting Qualitative research (COREQ statement ${ }^{20}$ ). The COREQ checklist can be found in the online supplemental appendix A1. This study was conducted within an explanatory sequential study design ${ }^{21}$ as follow-up to the Delphi study with patients. ${ }^{19}$

\section{Sampling, recruitment and data collection}

Participants were invited to participate via convenience sampling. Participants were eligible if they were at least 18 years of age and belonged to one of four chronic disease groups (cancer, mental disorders, cardiovascular diseases and musculoskeletal disorders). In March 2019, we approached 32 individuals who were recruited via community-based strategies and had already participated in a focus group on patient-centred care in the past. ${ }^{22}$ In those focus groups, participants were asked to provide insight into examples of behaviour of healthcare practitioners they had experienced in the past (eg, how they communicated with participants). After the focus group, we asked the participants if they were also interested in participating in an individual interview as part of a separate study. All participants of the focus groups were eligible for this study because, during discussions, no apparent differences in responding behaviour was shown by the participants (eg, major formal thought disorders). Thirty-two patients indicated interest and 20 of them participated. Ten patients never responded to our invitation and two did not appear to the scheduled interview. All interviews were conducted in rooms of the Department of Medical Psychology. The interviews were conducted in German by SZ, a male psychologist and doctoral researcher with experience in the method and professional interest in understanding the patients' perspectives on PC. After the interview, participants received a financial compensation of $20 €$.

The interview guide (see online supplemental appendix A2) was piloted with a student assistant prior to the first interview.

After greeting the participant and explaining the procedure, participants were first asked about relevant positive and negative experiences in the healthcare system. After exploring experiences, their own idea of an optimal healthcare system was further discussed. Participants were able to express their thoughts, SZ only intervened if necessary or if the provided answer indicated that more content could be drawn out of it. At the end of the interview, participants were asked what they associate with the term 'patient-centredness'. By asking these questions, we wanted to examine what about healthcare is relevant to patients on a more detailed level compared with the Delphi study. ${ }^{19}$ For example, participants were able to explain which specific behaviours healthcare practitioners showed in their appointments that made the participants feel satisfied or comfortable in this specific 
situation or over the period of treatment. If participants were not able to understand the questions in the intended way, the interviewer (SZ) rephrased the question and asked in a different way to ensure understanding.

We assessed demographic and clinical characteristics of participants using a short written patient-reported survey at the end of the interview. Interviews were audiorecorded and field notes were made during the interview facilitating probing questions.

Regarding data saturation and based on other studies, we first estimated that $8-12$ interviews could suffice. ${ }^{23}$ However, because of the known variance of the topic we decided to schedule 20 interviews to make sure that we would not miss important content. After 16 interviews, the first author who conducted the interviews (SZ) had the impression that theoretical saturation was achieved but continued with the interviews that were already scheduled with participants in order to ensure that no relevant novel themes would emerge from further interviews.

\section{Data analysis}

Recordings were transcribed verbatim and imported to MAXQDA $^{24}$ for content analysis. We used a deductive and inductive approach based on prior studies ${ }^{81922}$ and new emerging themes so that we could use pre-existing dimensions as well as possibly new emerging aspects. Transcripts and results of data analysis were not returned to participants for feedback. SZ was the main coder, EC discussed critical sections with SZ. An exhaustive description of the coding tree can be found as a supplementary file (online supplemental appendix A3). Every aspect was a subcode of 1 of the 16 dimensions of the integrative model. ${ }^{8}$ Additionally, every aspect mentioned by participants was coded and analysed thematically in regard to patient-centred care as well as how much space the topic was given by individual participants. Furthermore, we analysed, how often specific aspects were mentioned over all interviews in order to determine major and minor themes. For qualitative data analysis, we used MAXQDA, descriptive statistics of demographic and clinical data were calculated using SPSS V.23. ${ }^{25}$ Furthermore, the results were split by the first author (SZ) into major and minor themes and not into single categories (according to the definitions of Vaismoradi et $a l^{26}$ ) for easier interpretation. Major and minor themes thus represent coherent aspects of patient-centred care describing a specific aspect in general. Major themes are aspects, which were reported by the majority of participants and which a lot of time was allocated to by the participants, whereas minor themes were also mentioned frequently and described in detail, but not as extensively as major themes.

\section{Patient and public involvement}

We did not involve patients in the development of the research questions. However, we obtained collaboration agreements with several federal and regional patient organisations during the development of the research proposal and prior to submission to the funding agency in order to secure field access and feasibility. We approached patient organisations for that purpose. All gave us positive feedback on the study aims, acknowledging that more research is needed on patients' experiences related to PC care. Thus, patient organisations supported recruitment of study participants by disseminating advertisement for study participation. No individual patient was involved in recruitment and conduct of the study. All study participants and every interested person in the public have the possibility to read and download regular project updates and study results on the project website (http://www.ham-net.de/de/ projekte/projekt-aspired.html).

\section{RESULTS}

\section{Description of sample}

All 20 participants provided demographic and clinical data. Mean age was 52 (range: 30-79 years) and the sample was predominantly female $(85 \%)$. A detailed description can be found in table 1 .

\section{Major and minor themes}

An overview of all major and minor themes can be found in box 1. Interviews lasted $30 \mathrm{~min}$ on average (range: 24-35 min).

\section{Major themes \\ Competence, empathy and taking patients seriously}

The characteristics of HCPs are one of the three major themes that occurred frequently and extensively. Hereby, a set of distinctive traits were commonly used by participants to describe how HCPs should act towards patients. First, patients should be treated by competent HCPs that are skillful and knowledgeable. One participant stated (...) I want to be treated by the doctor and I have trust that he [or she] correctly and competently treats me. Otherwise, I could consult Google, you know' (Interview 9). Furthermore, participants wanted HCPs to take them seriously and not disregard their distress or symptoms. Many felt that their own perception and experience with their disease was disregarded instead of considering them as experts for their own body. This could be helpful for the correct diagnosis and treatment. The following quote illustrates this experience well:

And then, they [the staff] looked at it [a rash the patient had shown to her physician several times before] and she [the physician] said: 'Oh yes, indeed, an allergic reaction'. And I was thinking, great, what did I just say? Do they really think patients are that dumb?' (Interview 18).

Lastly, participants wanted HCPs to show empathy towards them: 'So, I am missing humanity, empathy, this is what I had wished more' (Interview 18). 


\begin{tabular}{|c|c|}
\hline Characteristics & Frequency \\
\hline Age (in years) & $M=52.05(S D=15.05)$ \\
\hline \multicolumn{2}{|l|}{ Sex } \\
\hline Female & $17(85 \%)$ \\
\hline Male & $3(15 \%)$ \\
\hline \multicolumn{2}{|l|}{ First language } \\
\hline German & $19(95 \%)$ \\
\hline Other & $1(5 \%)$ \\
\hline \multicolumn{2}{|c|}{ Chronic disease group (multiple answers possible) } \\
\hline Mental disorder & $15(75 \%)$ \\
\hline Musculoskeletal disorder & $9(45 \%)$ \\
\hline Cardiovascular disease & $7(35 \%)$ \\
\hline Cancer & $3(15 \%)$ \\
\hline Other* & $14(70 \%)$ \\
\hline \multicolumn{2}{|l|}{ Relationship status } \\
\hline Single & $12(60 \%)$ \\
\hline Married & $4(20 \%)$ \\
\hline Divorced & $4(20 \%)$ \\
\hline \multicolumn{2}{|l|}{ Education } \\
\hline Without diploma & $1(5 \%)$ \\
\hline Middle-school diploma & $9(45 \%)$ \\
\hline High-school diploma & $5(25 \%)$ \\
\hline University/college diploma & $5(25 \%)$ \\
\hline \multicolumn{2}{|l|}{ Employment status } \\
\hline Employed & $3(15 \%)$ \\
\hline Non-working & $3(15 \%)$ \\
\hline Retired† & $8(40 \%)$ \\
\hline Others $\ddagger$ & $6(30 \%)$ \\
\hline
\end{tabular}

*Other diseases include (but are not limited to) Hashimoto's thyreoditis, Infection with HIV, migraine, psoriasis or irritable bowel syndrome. These diseases were written on the questionnaire by participants prompted by an open answer category.

†Retired includes all types of retirement (eg, early retirement or retirement due to sickness).

$\ddagger$ Other employment statuses include for example being off sick or volunteer work.

\section{Time appropriate access to care}

Another major theme emerged from the fact that time is a very limited resource in healthcare, which can result in negative experiences for patients. Participants frequently told us that they had to wait a long time for an urgent appointment: 'I think it is inappropriate, if someone is in deep pain or had an accident; it just can't be that you'll get an appointment in sixweeks' (Interview 7). Additionally, participants wished for longer consultations. They understand that time is an essential and limited resource in healthcare. Still, they felt that conversations with less time pressure could provide a better exchange of information for both the physician and the patient: 'So, there aren't any

\section{Box 1 Overview of major and minor themes}

Major themes

Competence, empathy and taking patients seriously

Time appropriate access to care

Acknowledgement of the patient's individual situation

Minor themes

Taking a holistic perspective of the patient

Patient-centred communication

Integration of multidisciplinary treatment elements

Transparency regarding waiting time

Reduction of unequal access to care

long conversations. (...) everything is short and concise, and I understand, but this has to be changed urgently in my opinion, so that there will be more time for conversations with patients' (Interview 12).

\section{Acknowledgement of the patients' individual situation}

The last major theme revolves around being treated as a human being with fears, worries, wishes and needs. Patients reported being in a highly vulnerable state of illness, so it should be important for HCPs to understand that it is a stressful and exceptional situation for patients. They wanted to be met with respect and appreciation for their individual situation. Two quotes demonstrate the core of this theme. One participant described how it should be: 'So I was there - and I felt like I was seen as a human being and not like a random number' (Interview 11). The second quote illustrates a negative experience:

The nurses, they always babbled, always: 'You need to do it like this, everybody knows this'. One nurse hissed at me. And every time, I said: 'Excuse me, but this is my first time in the hospital and this is my first child I delivered'. (Interview 7)

\section{Minor themes}

Taking a holistic perspective of the patient

The first minor theme was that participants wished that HCPs would take a biopsychosocial perspective on their health condition and acknowledge the connection between body and mind. One quote demonstrates this well:

I once was in the psychiatric hospital for a longer stay and was $(. .$.$) referred to further specialists in an outpa-$ tient setting. They did not only look at my psychiatric disorders but also on every other aspect, it was holistic and they also focused on my body. (Interview 9)

\section{Patient-centred communication}

Participants wanted to receive information on their condition. They also wanted to be listened to when they are presenting their own information to the HCPs. Therefore, participants wanted HCPs to use terms easy to understand, to listen attentively and to focus on the patient instead of the computer: 
The HCPs always (...) look up something in the computer. They won't even look at you. (...) I want them to look me in the eyes and in those five min, I don't want them to play with the computer, I want them to be directed towards me and to listen to me and to treat me friendly. (Interview 7)

\section{Integration of multidisciplinary treatment elements}

Another minor theme was the wish of participants to not only focus on conventional medicine but to also be able to explore or to integrate complementary or additional treatments. Participants wished that their HCPs were more open to talk about and to integrate multidisciplinary treatment elements, for example, possible massages, physiotherapy, support groups, complementary medicine or herbal medicine. One participant got further additional elements for her own treatment and profited a lot, as she said:

So you'll get massages, you can talk to them, physiotherapy, and yes, exercise therapy. All together and also psychosomatic conversations and help for eating disorders. It is evident that a physician is not able to provide everything on his own and it is important to integrate those things nevertheless. (Interview 3)

\section{Transparency regarding waiting time}

A further minor theme was that participants, as seen above, understand that time is very limited in medical encounters and that delays in scheduled appointments can occur due to emergencies for example. Nevertheless, participants wished to be better informed about the time they will have to wait. The best option would be to reduce the waiting time in general. However, if that is not possible, participants wanted at least to receive transparent information about the reasons for delay and about the estimated remaining waiting time. Here are few examples on the perspectives of participants: 'Not knowing, what the physician does next. I want to be part of it. I want to get explanations' (Interview 6) and 'What I want to say, after having. waited two and a half hours (...) I still needed to wait and that was okay, because I knew, it could get longer' (Interview 12).

\section{Reduction of unequal access to care}

The final minor theme is related to the fact that universal health coverage in Germany is delivered in a public (statutory) and private health insurance. Participants with public health insurance described that they experienced unequal access to care, compared with patients with private health insurance, that is, they experienced longer waiting times for an appointment. This results in a feeling of being a second-class patient as one participant describes very vividly:

I called the physician twice and disguised myself as someone else for the second call so that I would know if I really have to wait 7 weeks for an appointment.
Table 2 Mapping of aspects to dimensions of patientcentred care

\begin{tabular}{|c|c|}
\hline $\begin{array}{l}\text { Dimension of the } \\
\text { integrative model }\end{array}$ & $\begin{array}{l}\text { Theme mentioned by patients } \\
\text { in the interviews }\end{array}$ \\
\hline $\begin{array}{l}\text { Essential characteristics } \\
\text { of the clinician }\end{array}$ & $\begin{array}{l}\text { Competence, empathy and } \\
\text { taking patients seriously (major } \\
\text { theme) }\end{array}$ \\
\hline $\begin{array}{l}\text { Patient as a unique } \\
\text { person }\end{array}$ & $\begin{array}{l}\text { Acknowledgement of the } \\
\text { patient's individual situation } \\
\text { (major theme) }\end{array}$ \\
\hline $\begin{array}{l}\text { Biopsychosocial } \\
\text { perspective }\end{array}$ & $\begin{array}{l}\text { Taking a holistic perspective of } \\
\text { the patient (minor theme) }\end{array}$ \\
\hline Access to care & $\begin{array}{l}\text { Time appropriate access to } \\
\text { care (major theme) } \\
\text { Reduction of unequal access } \\
\text { to care (minor theme) }\end{array}$ \\
\hline $\begin{array}{l}\text { Integration of medical and } \\
\text { non-medical care }\end{array}$ & $\begin{array}{l}\text { Integration of multidisciplinary } \\
\text { treatment elements (minor } \\
\text { theme) }\end{array}$ \\
\hline $\begin{array}{l}\text { Clinician-patient } \\
\text { communication }\end{array}$ & $\begin{array}{l}\text { Patient-centred } \\
\text { communication (minor theme) } \\
\text { Transparency regarding } \\
\text { waiting time (minor theme) }\end{array}$ \\
\hline
\end{tabular}

Nope, I could have come next Tuesday if I was privately insured. (Interview 12)

\section{Summary of results}

For an illustration, see table 2 for an overview mapping all major/minor themes to the 16 dimensions of the aforementioned model. ${ }^{819}$

\section{DISCUSSION}

This study adds the patients' perspective on specific aspects of $\mathrm{PC}$ and broadens therefore the knowledge about what patients consider relevant about PC. The study yielded three major themes: (1) competence, empathy and taking patients seriously; (2) time appropriate access to care; (3) acknowledgement of the patients' individual situation. Furthermore, the following minor themes emerged: (1) taking a holistic perspective; (2) patientcentred communication; (3) integration of multidisciplinary treatment elements; (4) transparency regarding waiting time; (5) reduction of unequal access to care. Notably, next to empathy and respect the aspect of 'being taken seriously by HCPs' which was missing in previous work on $\mathrm{PC}^{81319}$ was highlighted within the interviews.

This is not the first qualitative study to explore patients' experiences and needs regarding patient-centred healthcare (eg,Dierks and Bitzer ${ }^{27}$ or Maassen et $\left.a l^{17}\right)$. In 1999, Dierks and Bitzer ${ }^{27}$ found among other things that patients in Germany expect to be seen as individuals and from a holistic perspective, which is comparable to our results. Maasen and colleagues ${ }^{17}$ recently found that psychiatric patients mostly wanted HCPs to listen without 
judgements. Also in line with existing literature, ${ }^{28}$ some participants with a statutory health insurance reported unequal access to care compared with privately insured patients.

This study broadens the research on the patients' perspective on $\mathrm{PC}$ which has been underrepresented and complements the already existing literature well. As written above, PC was explored on the level of specific aspects instead of dimensions. Thus, it is now more distinct which dimensions ${ }^{19}$ and, especially, which specific aspects patients consider relevant since we clearly mapped the mentioned aspects to our existing dimensions (see table 2). For example, if an organisation wanted to focus on fostering patient-centred care because they already knew that this dimension is highly relevant for patients, ${ }^{19}$ they now also know which aspects to possibly focus on the most. In their implementation (eg, via trainings/workshops), they could focus on HCPs listening more attentively, using simpler words and training HCPs and practice teams to communicate waiting times transparently. This helps in prioritising implementation strategies. However, that does not mean that other aspects like treating patients with respect are irrelevant to patients. It should always be seen as an addition. Therefore, individual HCPs and healthcare delivery organisations that want to foster PC can now see which dimensions are highly relevant to patients and what specific aspects within these dimensions are relevant to patients. Consequently, this study provides implications on how to provide more patientcentred healthcare (eg, if an intervention is planned but the organisation only wants to focus on the most relevant aspects).

\section{Strengths and limitations}

This study provides an explanation to the broader results of the Delphi study, ${ }^{19}$ further strengthens the evidence for the results and gathers more insights for more concise interpretations due to using a different method as well as a different population. A further advantage of this study was the approach to let patients freely talk about their own experiences and vision of an optimal healthcare system without restricting them with preselected dimensions to talk about. This provided a chance for patients to express their own perception authentically and allowed them to talk about problematic structures in the German healthcare system without a social desirability bias. However, this study also has limitations. One possible flaw is the self-selecting bias which could be accounted for the fact that many participants reported mostly negative aspects. This could limit variance in reporting different aspects by participants. Another limitation to our study is the predominantly female proportion in our sample and an over-representation of patients with mental disorders. Although it seems like male participants or participants with mental disorders did not show major discrepancies of reported aspects of PC, it still needs to be accounted as a possible restriction. Consequently, generalisation is only possible to a limited extent (as generalizability is often not primarily expected in qualitative studies like this one) ${ }^{29}$

\section{Future studies}

Regarding the limitations, this study provides several possibilities for further research. Since our study was conducted with a convenience sample, it could be interesting to know if similar results occurred with a second, independent sample (eg, purposive sampling or with different diseases compared with this study). This way, results of this study could be consolidated. Furthermore, this study yielded results related to the German healthcare system and are therefore not generalisable beyond this level. It would be interesting to know which aspects patients from other countries would depict. Additionally, a similar study with more male participants or different chronic disease groups could provide knowledge on the question how or if different aspects of patient-centred care need to be accounted for (eg, if specific aspects are more common in a subgroup). Finally, results could differ for patients in different settings, for example for patients receiving care for the first time (or for the first encounter) or in emergency situations.

\section{CONCLUSION}

In summary, our study provides an enrichment of the patients' perspective on PC. We showed which aspects of patient-centred healthcare seem to be most important to patients: being taken seriously, being treated competently and with empathy, being recognised as individuals in exceptional situations, having enough time during encounters and timely access to care. These results can be used to prioritise specific strategies to foster implementation of patient-centred care.

Acknowledgements We thank our student assistant Tanja Kloster for supporting us preparing the manuscript and transcribing the interviews and our intern Cheyenne Topf for helping us developing the interview guide.

Contributors IS is the responsible principle investigator of the study. IS, EC, JMZ, $\mathrm{MH}$ and $\mathrm{AB}$ were involved in planning and preparation of the study. SZ recruited participants and collected data, and SZ analysed the data with help of EC. All authors interpreted the results. SZ wrote the first draft of the manuscript. IS, EC, $\mathrm{JMZ}, \mathrm{MH}$ and $\mathrm{AB}$ critically revised the manuscript for important intellectual content. All authors gave final approval of the version to be published and agreed to be accountable for the work.

Funding This study is funded by the German Federal Ministry of Education and Research (Bundesministerium für Bildung und Forschung - BMBF) with the grant number $01 \mathrm{GY} 1614$.

Disclaimer The funder had no role in decision to publish or preparation of the manuscript.

Competing interests None declared.

Patient consent for publication Not required.

Ethics approval The study was carried out according to the latest version of the Helsinki Declaration of the World Medical Association. Principles of good scientific practice were respected. The study had been approved by the Ethics Committee of the Medical Association Hamburg (study ID: PV5724). Study participation was voluntary and no foreseeable risks for participants resulted from the participation in this study. Participants were fully informed about the aims of the study, data collection and the use of collected data. Written informed consent was obtained 
prior to participation (see online supplemental appendix A4). Preserving principles of data sensitivity, data protection and confidentiality requirements were met.

Provenance and peer review Not commissioned; externally peer reviewed.

Data availability statement Data are available upon reasonable request. All data relevant to the study are included in the article or uploaded as supplemental information.

Supplemental material This content has been supplied by the author(s). It has not been vetted by BMJ Publishing Group Limited (BMJ) and may not have been peer-reviewed. Any opinions or recommendations discussed are solely those of the author(s) and are not endorsed by BMJ. BMJ disclaims all liability and responsibility arising from any reliance placed on the content. Where the content includes any translated material, BMJ does not warrant the accuracy and reliability of the translations (including but not limited to local regulations, clinical guidelines, terminology, drug names and drug dosages), and is not responsible for any error and/or omissions arising from translation and adaptation or otherwise.

Open access This is an open access article distributed in accordance with the Creative Commons Attribution Non Commercial (CC BY-NC 4.0) license, which permits others to distribute, remix, adapt, build upon this work non-commercially, and license their derivative works on different terms, provided the original work is properly cited, appropriate credit is given, any changes made indicated, and the use is non-commercial. See: http://creativecommons.org/licenses/by-nc/4.0/.

\section{ORCID iDs}

Stefan Zeh http://orcid.org/0000-0002-1748-3155

Eva Christalle http://orcid.org/0000-0001-7813-5800

Jördis M Zill http://orcid.org/0000-0001-8995-5556

Martin Härter http://orcid.org/0000-0001-7443-9890

Andreas Block http://orcid.org/0000-0003-3544-2194

Isabelle Scholl http://orcid.org/0000-0002-7639-0880

\section{REFERENCES}

1 Baumgart J. Ärzte und informierte Patienten: Ambivalentes Verhältnis. Deutsches Ärzteblatt:2-5 [Accessed 18 Nov 2020].

2 Deutscher Bundestag. Bundesrat: Gesetzesbeschluss 2008.

3 Härter M, Dirmaier J, Scholl I, et al. The long way of implementing patient-centered care and shared decision making in Germany. $Z$ Evid Fortbild Qual Gesundhwes 2017;123-124:46-51.

4 Rathert C, Wyrwich MD, Boren SA. Patient-centered care and outcomes: a systematic review of the literature. Med Care Res Rev 2013;70:351-79.

5 Dwamena F, Holmes-Rovner M, Gaulden CM, et al. Interventions for providers to promote a patient-centred approach in clinical consultations. Cochrane Database Syst Rev 2012;12:CD003267.

6 McMillan SS, Kendall E, Sav A, et al. Patient-centered approaches to health care: a systematic review of randomized controlled trials. Med Care Res Rev 2013;70:567-96.

7 van Dulmen S. Patient-centredness. Patient Educ Couns 2003;51:195-6.

8 Scholl I, Zill JM, Härter M, et al. An integrative model of patientcenteredness - a systematic review and concept analysis. PLoS One 2014;9:e107828.
9 Stewart M, Brown JB, Weston WW. Patient-Centered medicine. CRC Press, 2013.

10 Ouwens M, Hermens R, Hulscher M, et al. Development of indicators for patient-centred cancer care. Support Care Cancer 2010;18:121-30.

11 Mead N, Bower P. Patient-centredness: a conceptual framework and review of the empirical literature. Soc Sci Med 2000;51:1087-110.

12 Epstein RM, Franks P, Fiscella K, et al. Measuring patient-centered communication in patient-physician consultations: theoretical and practical issues. Soc Sci Med 2005;61:1516-28.

13 Zill JM, Scholl I, Härter M, et al. Which Dimensions of PatientCenteredness Matter? - Results of a Web-Based Expert Delphi Survey. PLoS One 2015;10:e0141978.

14 Luxford K. What does the patient know about quality? Int J Qual Health Care 2012;24:439-40.

15 Hudon C, Fortin M, Haggerty J, et al. Patient-centered care in chronic disease management: a thematic analysis of the literature in family medicine. Patient Educ Couns 2012;88:170-6.

16 Bensing J, Rimondini M, Visser A. What patients want. Patient Educ Couns 2013;90:287-90.

17 Maassen EF, Schrevel SJC, Dedding CWM, et al. Comparing patients' perspectives of "good care" in Dutch outpatient psychiatric services with academic perspectives of patient-centred care. J Ment Health 2017;26:84-94.

18 Vennedey V, Hower KI, Hillen $\mathrm{H}$, et al. Patients' perspectives of facilitators and barriers to patient-centred care: insights from qualitative patient interviews. BMJ Open 2020;10:e033449.

19 Zeh S, Christalle E, Hahlweg P, et al. Assessing the relevance and implementation of patient-centredness from the patients' perspective in Germany: results of a Delphi study. BMJ Open 2019;9:e031741.

20 Tong A, Sainsbury P, Craig J. Consolidated criteria for reporting qualitative research (COREQ): a 32-item checklist for interviews and focus groups. Int J Qual Health Care 2007;19:349-57.

21 Curry L, Nunez-Smith M. Mixed methods in health sciences research: a practical primer. Los Angeles: SAGE, 2015.

22 Christalle E, Zeh S, Hahlweg P, et al. Assessment of patient centredness through patient-reported experience measures (ASPIRED): protocol of a mixed-methods study. BMJ Open 2018;8:e025896.

23 Guest G, Bunce A, Johnson L. How many interviews are enough? Field methods 2006;18:59-82.

24 VERBI Software. MAXQDA: software für qualitative Datenanalyse. Berlin: Consult: 1989-2020.

25 IBM Corp. IBM SPSS statistics for windows. Armonk, NY: IBM Corp, 2020.

26 Vaismoradi $\mathrm{M}$, Jones $\mathrm{J}$, Turunen $\mathrm{H}$. Theme development in qualitative content analysis and thematic analysis. JNEP 2015;6.

27 Dierks M-L, Bitzer E. Wie kann man Erwartungen und Zufriedenheit der Patienten im Qualitätsmanagement berücksichtigen? Schriftenreihe des Bundesministeriums für Gesundheit;125:84.

28 Luque Ramos A, Hoffmann F, Spreckelsen O. Waiting times in primary care depending on insurance scheme in Germany. BMC Health Serv Res 2018;18:191.

29 Leung L. Validity, reliability, and generalizability in qualitative research. J Family Med Prim Care 2015;4:324-7. 